\title{
Revisiting the Child and Adolescent Survivors of 2004 Tsunami: A Follow-up Study
}

\author{
Braj Bhushan ${ }^{1, *}$, J. Sathya Kumar ${ }^{2}$ \\ ${ }^{1}$ Department of Humanities \& Social Sciences, Indian Institute of Technology Kanpur, Kanpur, India \\ ${ }^{2}$ Thiagarajar School of Management, Madurai, India \\ *Corresponding Author: brajb@iitk.ac.in
}

\begin{abstract}
December 26, 2004 tsunami waves were assessed for their current level of posttraumatic stress (PTS) and posttraumatic growth (PTG). The intrusive and avoidance reactions were compared against their baseline level measured in 2006. The effect of death of family members and rehabilitation experiences (stay in rehabilitation camp and receiving relief material) on the posttraumatic outcomes was examined. Further, the mediating effect of schema changes, coping, and cognitive-emotional regulation strategies on the relationship between baseline trauma and posttraumatic outcomes was also explored. The findings suggested an overall reduction in trauma level with significant decline in intrusion, avoidance, and total trauma in males. However, the intrusion level had increased in females. The findings also indicated significant sex difference with females scoring high on PTS as well as PTG. Self-blame mediated the relationship between baseline and current levels of avoidance as well as baseline avoidance and spiritual change. Reflective coping significantly mediated the relationship between baseline intrusion and relating to others and personal strength. It also mediated the relationship between baseline total trauma score and relating to others, personal strength, and spiritual change. Preventive coping mediated the relationship between intrusion and appreciation of life, whereas instrumental support seeking mediated the relationship between baseline avoidance and new possibilities and appreciation of life.
\end{abstract}

Keywords Posttraumatic Stress, Posttraumatic Growth, Cognitive-Emotional Regulation, Coping

\section{Introduction}

The cognitive processing models of trauma (Foa, Steketee, \& Rothbaum, 1989; Horowitz, 1986) propose that traumatic events radically change fundamental beliefs about the self, the world, and others. These models hypothesize that cognition, especially meaning given to the traumatic experience, influence posttraumatic schemas and mediate posttraumatic reactions. Although trauma studies have largely focused on posttraumatic stress disorder (PTSD), growing bodies of research have started focusing on the positive psychological changes experienced as a consequence of extremely challenging life circumstances. Such changes are referred to as posttraumatic growth (PTG) (Tedeschi \& Calhoun, 1995). Studies suggest that growth experiences far outnumber reports of psychiatric problems. It is estimated that between $30 \%-90 \%$ of the survivors report at least some positive changes following trauma (Tedeschi, Park \& Calhoun, 1998).

Tedeschi and Calhoun (2004) argue that posttraumatic growth and distress coexist. In a meta-analytical review of 87 cross-sectional PTG studies investigating the relationship among psychological health, physical health, stressor, personality, and coping, Helgeson, Reynolds, and Tomich (2006) found that benefit finding (PTG) was related to positive well-being, intrusion and avoidant thoughts about the stressor. Earlier studies have reported mixed findings. They have reported negative (Evers et al., 2001), positive (Lev-Wiesel \& Amir, 2003), and no correlation (Powell et al., 2003) between the symptoms of distress and growth. This necessitates reexamination of the nature of relationship between a traumatic experience and the posttraumatic outcomes. Our understanding of PTG is based on the study of adults. Recently researchers have begun studying PTG among adolescents, especially its relationship with PTSD (Barakat, Alderfer, \& Kazak, 2006; Levine et al., 2008; Milam, Ritt-Olson, \& Unger, 2004), much needs to be understood about this mechanism in children and adolescents.

Studies have consistently reported association between negative schemas and PTSD (Owens \& Chard, 2001; Ali et al., 2002). It is construed that the rebuilding of schemas in the positive direction may contribute to PTG. However, the role of schema changes in PTG is far from clear. As pointed out by Salmon and Bryant (2002), the cognitive theories of PTSD have evolved in the context of adult manifestation of trauma reactions and the "extent to which current information processing theories can adequately account for childhood PTSD is unclear" (p. 168). 
Emotion regulation plays a vital adaptive function. Study of the impact of such challenging life experiences also necessitates thorough investigation of the role of emotional and cognitive processes. According to Eisenberg et al. (2000), emotion regulation is "the process of initiating, maintaining, modulating, or changing the occurrence, intensity, or duration of internal feeling states and emotion-related physiological processes, often in the service of accomplishing one's goals" (p. 137). It essentially holds a number of physiological, cognitive, and behavioral regulatory processes (Thompson \& Calkins, 1996). Cognitive-emotional processing strategies are extremely important in determining the posttraumatic outcomes (Garnefski, Kraaij, \& Spinhoven, 2002). Investigating childhood PTSD, Bryant et al. (2007) have reported considerable effect of negative appraisals in the initial phase after trauma. They found one's ongoing vulnerability as the strongest predictor of PTSD whereas Meiser-Stedman et al. (2009) argue that negative appraisals of enduring change characterize PTSD in adolescents. "It is also possible that children who suffer different traumatic events may be more prone to engage in different appraisals" (Bryant et al., 2007, p. 2505).

It is important to understand cognitive-emotion regulation in the developmental perspective. The cognitive theories endorse that the appraisal of trauma and its consequences play role in the causation, maintenance, and intensification of behavioural reactions (Ehlers \& Clark, 2000). Thus, maladaptive appraisals mediate the relationship between initial reactions to trauma and the posttraumatic stress symptoms developing at a later stage. There is a paucity of research exploring how these maladaptive appraisals affect the unfolding of PTS in children and adolescents. The past two studies (Ehlers, Mayou \& Bryant, 2003; Stallard, 2003) have linked maladaptive appraisals to later PTS in younger populations. However, these studies did not show whether cognitive factors induced any variation in PTS symptoms or not. Later, Bryant et al. (2007) measured PTS level in the first month and again at six months in trauma-exposed youth and found maladaptive appraisals responsible for subsequent PTSD. It merits mention that none of these studies explored the mediating role of maladaptive appraisals in the development of PTG.

A key developmental issue is as to how trauma-related information influences the cognitive schema of children; obviously appraisal becomes extremely important. Studies have found that negative cognitions about the trauma and its consequences predict long-term PTSD in addition to initial symptom levels (Ehring et al., 2006, 2008; Halligan et al., 2003). The cross-sectional studies of the child and adolescent survivors endorse significant relations between appraisal of trauma and PTS (Meiser-Stedman et al., 2007; Salmon, Sinclair, \& Bryant, 2007).

The information processing theories also lay emphasis on using coping mechanisms for emotion regulation as it is a key component in the fear network. Coping refers to "the cognitive way of managing the intake of emotionally arousing information" (Thompson, 1991, p. 1659) that is influenced by social contacts and daily events (Pietilä \&Tervo, 1998). Besides inducing a sense of well-being it also arouse feeling of security and stability. According to Greenglass (2002), proactive coping "incorporates a confirmatory and positive approach to dealing with stressors..... integrates processes of personal quality of life management with those of self-regulatory goal attainment" (p. 37). Studies have found that proactive coping positively correlate with internal control and active coping (Greenglass et al., 1999) and life satisfaction and negatively with variables such as depression (Greenglass et al., 2006). Vernon, Dillon and Steiner (2009) also found a negative relationship between proactive coping style and traumatic experiences. There is clinching evidence suggesting coping as a mediator of posttraumatic stress reactions (Sharkansky, King, King, \& Wolfe, 2000). Although researchers have established coping strategies as a mediator in the relationship between life events and psychological distress (Hallis \& Slone, 1999), there is no consensus as to which coping strategies are most effective in reducing psychopathological and distress symptoms (Carr, 1988; Thoits, 1995). It merits mention that these details are derived from empirical investigations of adults and to the best of our knowledge it has not been studied on child and adolescent samples.

Western researchers have reported lower rates of PTSD (0-5\%) following natural disasters (Earls et al., 1988; Lonigan et al., 1994) which is far less than PTSD induced by other types of trauma. The effect of December 26, 2004 earthquake triggering tsunami waves on children and adolescents have been studied by several researchers in India (Bhushan\& Kumar, 2007, 2009; John, Russell, \& Russell, 2007; Vijayakumar, Kannan \& Daniel, 2006), as well as Sri Lanka (Neuner et al., 2006; Wickrama \& Kaspar, 2007), and Thiland (Griensven et al., 2006) and the estimates far exceeds the earlier figure. The colossal differences in these statistical figures coerce a re-look at the traumatic experiences reported by children and adolescents.

PTSD has been studied in children and adolescents (Lori \& Lawrence, 2003; Suliman, Kaminer, Seedat, \& Stein, 2005) although certain aspects of PTSD response manifest differently in younger population (Salmon \& Bryant, 2002). On the contrary, there are evidences in the literature suggesting similar PTSD symptoms in children as seen in adults (Fletcher, 1996; Yule, 1992). Empirical evidences supporting such processes in child and adolescent survivors of disasters are very little (Dalgleish, Meiser-Stedman, \& Smith, 2005; Meiser-Stedman, 2002). Further, the "existing cognitive theories do not give adequate attention to the role of social factors in the child's response to trauma" (Salmon \& Bryant, 2002, p. 169). Norris (2002) has reported that the consequences of disasters are more severe in developing countries. This has been reported by other researchers too (Bhushan, 2008). "...the overall disaster management in developing countries coerces prolonged displacement" 
(Bhushan \& Kumar, 2009, p. 37). Such delay in restoring normal life has the susceptibility of inducing behavioural disorders (Beiser \& Wickrama, 2004). Disaster mitigation and management has its own limitations and when combined with certain life circumstances and geo-cultural realities, the overall psychological consequence can be tremendous. We, therefore, also studied the effect of rehabilitation experiences on posttraumatic outcomes.

This study examines how the cognitive appraisals implicated in cognitive models of PTSD affect posttraumatic outcomes (PTS and PTG) in children and adolescents. It attempts to understand how such appraisals mediate indoctrination of the traumatic experiences. As stated earlier (Bhushan \& Kumar, 2007, 2009), we consider posttraumatic reactions not as disorder but as "normal reactions experienced by people in response to stressful and traumatic situations, indicative of need for cognitive-emotional processing, rather than an abnormal state of mind" (Joseph \& Williams, 2005, pp. 426). In our earlier study (Bhushan \& Kumar, 2007) we had assessed the level of posttraumatic stress (PTS) in child and adolescent survivors of tsunami at Nagapatinam district of Tamilnadu, India. After 5.2 years we decided to revisit these adolescents to see how they have evolved over time and odds. Schema changes, coping, and cognitive-emotional regulation strategies were examined as mediating variables between baseline trauma $\left(T_{1}\right)$ and current level of trauma $\left(\mathrm{T}_{2}\right)$. Considering the time lapse since the actual event, we also explored posttraumatic growth in these adolescents. As cognitive variables were measured only at $T_{2}$, temporal priority cannot be given to the mediators over the outcome. It merits mention that the priority between the variables cannot be determined beforehand and the assumption of influence of cognitive variables on PTS and PTG (and not the other way round) is based on theories. This study examined whether schema changes, coping strategies, and cognitive-emotional regulation affected the current level of posttraumatic outcomes or not. Further, the impact of rehabilitation experiences was also explored. This study tested following hypotheses-

i. The current level of PTS $\left(\mathrm{T}_{2}\right)$ should be less than the baseline $\left(\mathrm{T}_{1}\right)$;

ii. Schema changes (negative cognition about the self, negative cognition about the world, and self-blame) would mediate the relationship between baseline trauma and posttraumatic outcomes (PTS and PTG);

iii. Coping strategies (proactive, reflective, strategic, preventive, instrumental, emotional, and avoidance) would mediate the relationship between baseline trauma and the posttraumatic outcomes (PTS and PTG);

iv. Cognitive-emotional regulation strategies (self-blame, other-blame, rumination, catastrophizing, putting into perspective, positive refocusing, positive reappraisal, acceptance, and planning) would mediate the relationship between baseline trauma and the posttraumatic outcomes
(PTS and PTG);

v. Life experiences (death of family members) and rehabilitation experiences (stay in rehabilitation camp and receiving relief material) would affect posttraumatic outcomes (PTS and PTG);

vi. The coalesce of life experience (death of family members) and stay in rehabilitation camp would affect posttraumatic outcomes (PTS and PTG);

vii. Males and females would significantly differ on all the dimensions of posttraumatic outcomes; and viii. Males and females would significantly differ in terms of schema changes, coping, and cognitive-emotional regulation strategies.

\section{Method}

\section{Sample}

The baseline study $\left(T_{1}\right)$ was conducted on 130 participants from Akkaraipettai village of Nagapatinam district of Tamilnadu, India. Communality of trauma related characteristics was the inclusive criteria. The participants did not differ in terms of injury type, previous trauma history, and socio-economic status. All of them belonged to the same geopolitical area and ethnic group. Five years two months later we visited them again to carry out the second phase $\left(\mathrm{T}_{2}\right)$ of the study. 82 (41 boys and 41 girls) of the earlier 130 participants participated in the second phase. The age of the subjects $\left(\right.$ at $\mathrm{T}_{2}$ ) ranged between 12-17 years (M 14.69, SD .94). Psychological assistance and further traumatic experience(s) during the interval phase were the exclusion criteria. Seven participants were excluded from study because of incomplete data. The remaining participants either declined to participate or were not reachable.

\section{Measures}

The 15-item Impact of event scale (IES; Horowitz, Wilner, \& Alvarez, 1979) was administered to assess the experiences of avoidance and intrusion in the participants. These are indicators of the intensity of the posttraumatic stress. Of the 15 items, 7 assess intrusive symptoms and 8 measure avoidance. All the items of the IES are anchored to a specific stressor. The split-half reliability for the whole scale has been reported to be .86 (Horowitz et al., 1979). Researchers have used IES on children and adolescents too (Barakat et al., 2006; Bhushan \& Kumar, 2007, 2009). The reliability of the adapted version used in the present study was .82 and .89 , respectively for intrusion and avoidance.

The 55-item Proactive Coping Inventory (PCI, Greenglass et al., 1999) consists of seven dimensions- proactive, reflective, strategic, preventive, instrumental, emotional, and avoidance coping. It was administered to determine the type of coping strategy used by the participants. The reported Cronbach's alpha coefficients for proactive (.85), reflective (.79), strategic (.71), preventive (.83), instrumental (.85), emotional (.73), and avoidance (.74) coping are very high. Bhushan, Gautam, and Greenglass's (2010) Indian 
adaptation of PCI shows psychometrically acceptable reliabilities ranging from .64 to .85 for different subscales and overall scale reliability of .91 .

Cognitive Emotion Regulation Questionnaire (CERQ; Garnefski et al., 2001, 2002) is a 36-item questionnaire consisting of 9 distinct subscales- self-blame, other-blame, rumination, catastrophizing, putting into perspective, positive refocusing, positive reappraisal, acceptance, and planning that measures cognitive strategies characterizing one's style of responding to stressful events as well as cognitive strategies used in such situation. Each subscale of CERQ refers to distinct cognitive strategy used by people after stressful experiences. According to Garnefski et al. (2001), the test-retest reliability range between 0.41 and 0.59 . Hussain \&Bhushan's (2011) Indian adaptation of CERQ is psychometrically acceptable with Cronbach's alpha coefficients ranging from .56 to .78 .

Posttraumatic Cognition Inventory (PTCI; Foa et al., 1999) is a 33-item scale consisting three subscales- negative cognitions about the self, negative cognitions about the world, and self blame. The reported internal consistency is sound for the whole scale (total score, $\alpha=.97$ ) as well as the three subscales (negative cognitions about the self, $\alpha=.97$; negative cognitions about the world, $\alpha=.88$; self-blame, $\alpha$ $=.86)$. Test-retest reliability for a 1 week interval ranged from .75 to .89 and for a 3 -week interval from .80 to .86 for the three subscales. According to Foa et al. (1999), PTCI has also been found suitable to differentiate individuals with and without PTSD (sensitivity $=.78$, specificity $=.93$ ). The Cronbach's alpha coefficients are .85 (negative cognitions about the self), .77 (negative cognitions about the world), and .73 (self-blame) for the Indian adaptation (Hussain, 2010).

Posttraumatic Growth Inventory (PTGI; Tedeschi \& Calhoun, 1995, 1996) consists of 21 items. It measures 5 dimensions of PTG- relating to others ( 7 items), new possibilities (5 items), personal strength (4 items), spiritual change (2 items), and appreciation of life (3 items). The test-retest reliabilities for the factors range from .65 to .74, except for personal strength $(\mathrm{r}=.37)$ and appreciation of life $(\mathrm{r}=.47)$. The Cronbach's alpha coefficient for the Indian adaptation (Hussain, 2010) range between .48 and .88, and the alpha coefficient of the total scale is .86. PTGI has been used by researchers on adolescent population (Levine et al., 2008).

\section{Procedure}

The ground reality at $T_{1}$ was pathetic, something that only those who have visited the site can realize. After due deliberation with the stakeholders we decided to administer only IES along with collection of demographic and trauma related details at $\mathrm{T}_{1}$. The remaining measures (PCI, CERQ, PTCI, and PTGI) were administered along with IES at $\mathrm{T}_{2}$. The Indian adaptations of the measures were administered. The first phase of data collection was carried out in a school in the community that was converted into a rehabilitation camp. At $\mathrm{T}_{2}$ this building was fully operational as a community school. The participants were briefed about the purpose and voluntary nature of participation and all those who consented were given a booklet comprising the questionnaires. All the questionnaires were self-administered. The participants were given the booklet after receiving their consent. They were free not to respond to an item deemed stress provoking. They also had the liberty to quit, if felt so.

\section{Results}

\section{Baseline $\left(T_{1}\right)$ and current level of trauma $\left(T_{2}\right)$}

A comparison was made between the baseline and the current status of trauma level (Table 1a). The mean of baseline intrusion was 23.61 (SD 4.69) whereas the mean of current level of intrusion was 22.94 (SD 6.61) suggesting no significant change in the intrusion level of the participants. A significant reduction in the level of avoidance was seen. This was also found for the total trauma score. The baseline and current mean of avoidance were 25.15 (SD 6.79) and 18.66 (SD 4.76), respectively. The two mean scores were significantly different $(\mathrm{t}=-6.38, p<.000)$. The mean baseline and current total trauma score were 48.76 (SD 8.96) and 41.60 (SD 8.79), respectively. t-test indicated a significant difference between the two scores $(\mathrm{t}=-5.51, p<.000)$ with significant reduction from the baseline trauma level. Thus, the first hypothesis was partially accepted as intrusive thoughts have not reduced significantly.

When the comparison of the baseline and current mean scores of intrusion, avoidance, and total trauma were performed separately for males and females, a distinct finding was observed (see table 1b). The current scores of males were significantly lower than the baseline for intrusion $(\mathrm{t}=3.80, p<.000)$, avoidance $(\mathrm{t}=8.81, p<.000)$, and total trauma $(\mathrm{t}=9.62, p<.000)$. However, the current intrusion level in females was significantly more than the baseline $(\mathrm{t}=$ $-3.59, p<.001)$. The difference between baseline and current level of avoidance and total trauma scores were not significant. 
Table 1a. t-test comparison between baseline (T1) and current (T2) levels of trauma.

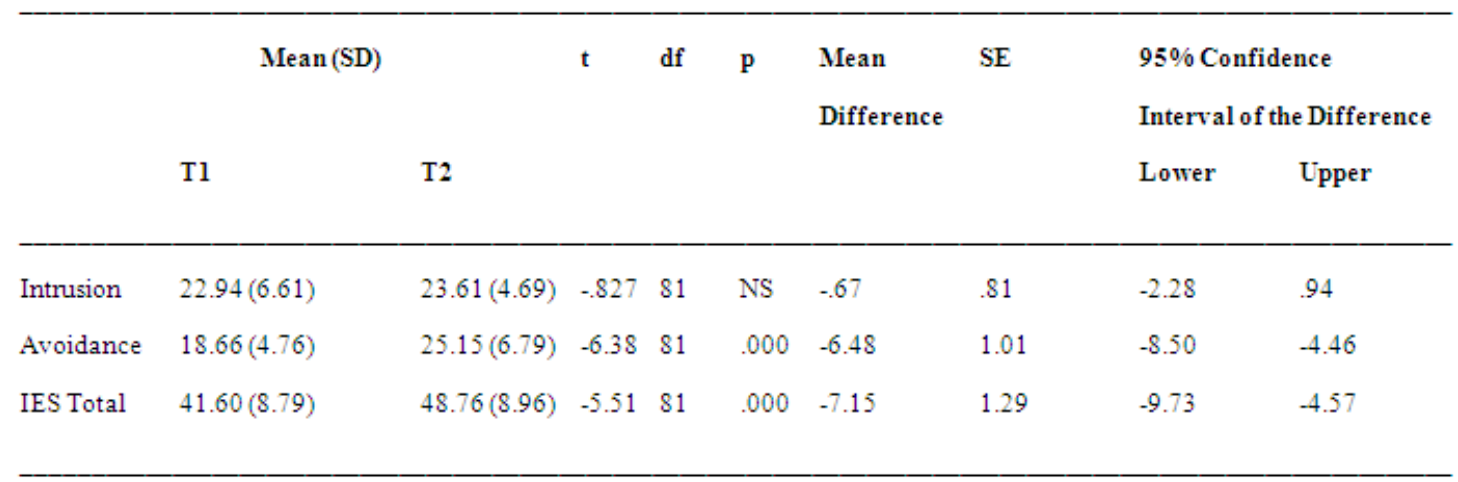

Table 1b. t-test comparison for sex difference between baseline $\left(\mathrm{T}_{1}\right)$ and current $\left(\mathrm{T}_{2}\right)$ levels of trauma.

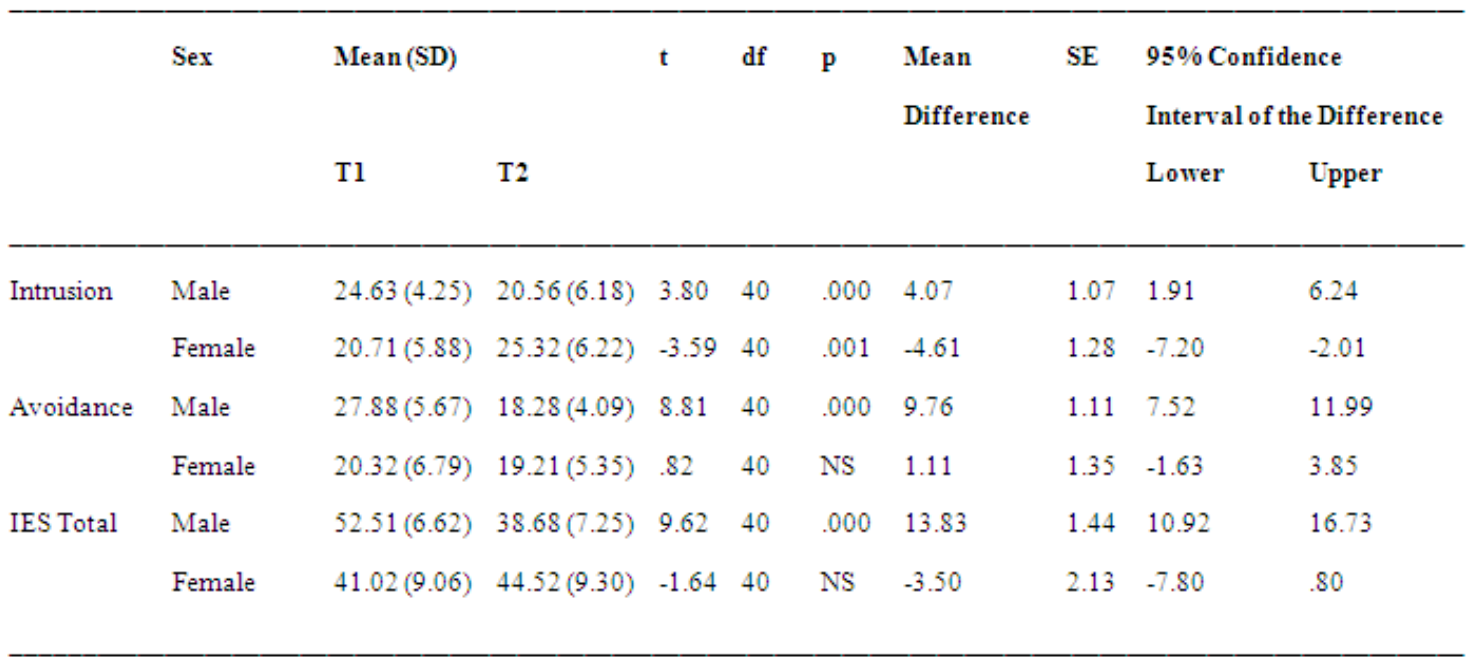

\section{Mediating effects of schema changes, coping strategies, and cognitive-emotional regulations}

In order to see whether schema changes, coping strategies, and cognitive-emotional processes mediated the relationship between the baseline and current levels of trauma, mediation regression analysis was performed. Considering baseline trauma level as independent variable, the mediating effect of cognitive-emotional regulations, posttraumatic cognition and coping strategies on the current status of intrusion, avoidance, and total trauma score of the tsunami survivors were examined. The mediating effects of these variables on the relationship between baseline trauma and PTG were also performed. Sobel test was performed to see the indirect effect of the independent variable on the dependent variable through the mediator variable using the formula drawn from MacKinnon, Warsi, and Dwyer (1995)-

$$
\text { Sobel } \mathrm{z}=\mathrm{a} \text { *b/SQRT }\left(\mathrm{b}^{2} \mathrm{~s}_{\mathrm{a}}{ }^{2}+\mathrm{a}^{2} \mathrm{~s}_{\mathrm{b}}{ }^{2}\right)
$$

Where $\mathrm{a}=$ regression coefficient for the association between independent variable and mediator

$$
\mathrm{s}_{\mathrm{a}}=\text { standard error of } \mathrm{a}
$$

$b=$ regression coefficient for the association between the mediating and dependent variables

$$
\mathrm{s}_{\mathrm{b}}=\text { standard error of } \mathrm{b}
$$

As summarized in Table 2, only self-blame dimension of CERQ significantly mediated the relationship between baseline and current levels of avoidance $(\mathrm{F}(1,80)=5.149$, $\mathrm{p}<.026, \beta=.246, \mathrm{R}^{2}=.060$, Sobel $\left.\mathrm{Z}=-1.98, p<.04\right)$. The mediating effects of rest of the CERQ strategies, coping strategies, and posttraumatic cognition were statistically not significant for PTS. Acceptance mediated the relationship between baseline avoidance and spiritual change $(F(1,80)=$ $7.908, \mathrm{p}<.006, \beta=-.300, \mathrm{R}^{2}=.090$, Sobel $\mathrm{Z}=2.08, p<.03$ ) dimension of PTG. Reflective coping significantly mediated the relationship between baseline intrusion and relating to others $\left(\mathrm{F}(1,80)=7.719, \mathrm{p}<.007, \beta=.381, \mathrm{R}^{2}=.088\right.$, Sobel $\mathrm{Z}=-1.95, p<.05)$, personal strength $(\mathrm{F}(1,80)=24.516$, $\mathrm{p}<.000, \beta=.437, \mathrm{R}^{2}=.235$, Sobel $\left.\mathrm{Z}=2.39, p<.01\right)$ dimensions of PTG, and total PTG score $(\mathrm{F}(1,80)=13.913$, $\mathrm{p}<. .000, \beta=1.239, \mathrm{R}^{2}=.148$, Sobel $\left.\mathrm{Z}=2.20, p<.02\right)$ whereas preventive coping mediated the relationship between intrusion and appreciation of life $(\mathrm{F}(1,80)=23.75$, 
$\mathrm{p}<.000, \beta=.281, \mathrm{R}^{2}=.229$, Sobel $\left.\mathrm{Z}=1.89, p<.05\right)$. Reflective coping also significantly mediated the relationship between total trauma score (baseline) and relating to others $\left(\mathrm{F}(1,80)=7.719, \mathrm{p}<.007, \beta=.297, \mathrm{R}^{2}\right.$ $=.088$, Sobel $\mathrm{Z}=2.00, p<.04)$, personal strength $(\mathrm{F}(1,80)=$ $24.516, \mathrm{p}<.000, \beta=.484, \mathrm{R}^{2}=.235$, Sobel $\left.\mathrm{Z}=2.49, p<.01\right)$, spiritual change $\left(\mathrm{F}(1,80)=6.332, \mathrm{p}<.014, \beta=.271, \mathrm{R}^{2}\right.$ $=.073$, Sobel $\mathrm{Z}=1.90, p<.05)$, and total PTG score $(\mathrm{F}(1,80)$ $=13.91, \mathrm{p}<.000, \beta=.385, \mathrm{R}^{2}=.148$, Sobel $\left.\mathrm{Z}=2.28, p<.02\right)$.
Instrumental support seeking mediated the relationship between baseline avoidance and new possibilities $(\mathrm{F}(1,80)$ $=5.226, \mathrm{p}<.025, \beta=.248, \mathrm{R}^{2}=.061$, Sobel $\left.\mathrm{Z}=-1.95, p<.05\right)$ and appreciation of life $(\mathrm{F}(1,80)=4.869, \mathrm{p}<.030, \beta=.240$, $\mathrm{R}^{2}=.057$, Sobel $\left.\mathrm{Z}=-1.91, p<.05\right)$. Although these findings extend partial support to the second, third, and fourth hypothesis, they do confirm the significance of cognitive-emotional regulations, posttraumatic cognition, and posttraumatic growth.

Table 2. Mediational regression analysis for PTS and PTG (with Sobel test outcomes).

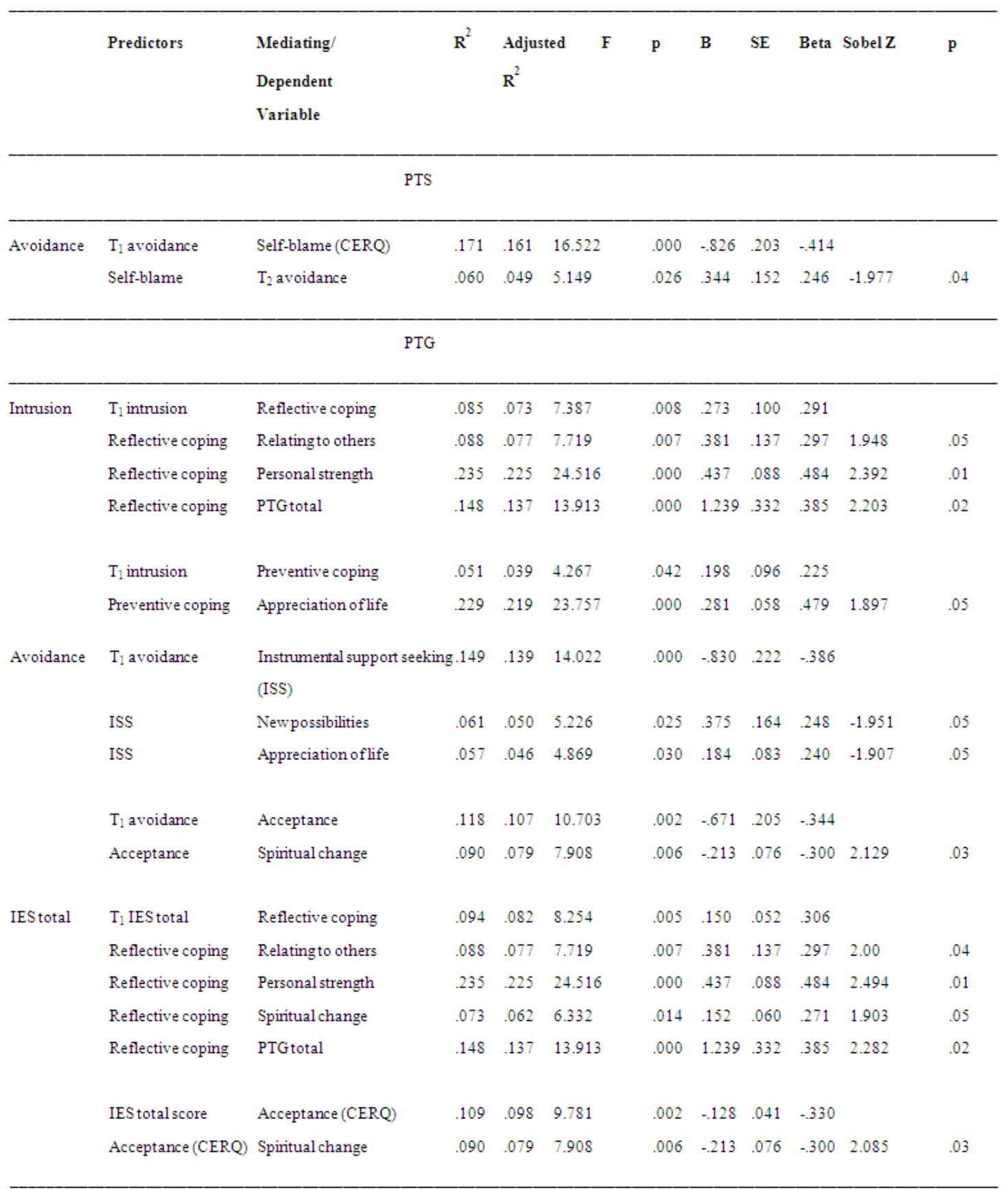


Table 3. Summary of Multivariate Analysis of Variance.

\begin{tabular}{lccccc}
\hline Source of Variation & Wilks' Lambda & F & Hypothesis df & Error df & p \\
\hline Sex & .741 & 3.239 & 7 & 65 & .005 \\
Death of family member & .783 & 2.578 & 7 & 65 & .021 \\
Stay in rehabilitation camp & .768 & 2.811 & 7 & 65 & .013 \\
Death of family member x Stay in rehabilitationcamp & .815 & 2.111 & 7 & 65 & .055 \\
\end{tabular}

\section{MANOVA testing the effect of life and rehabilitation experiences}

To test the effect of life (death of family members) and rehabilitation experiences (stay in rehabilitation camp and receiving relief material) on the posttraumatic outcomes, the observed data was subjected to multivariate analysis of variance (MANOVA) with sex, death of family member(s), and stay in the rehabilitation camp as independent variables and trauma (intrusion, avoidance, and total trauma) and posttraumatic growth (relating to others, new possibilities, personal strength, spiritual change and appreciation of life) as dependent variables. As detailed in Table 3, the main effects of sex (Wilk's lambda $=.741, \mathrm{~F}_{7,65}=3.239, p<.005$ ), death of family member(s) (Wilk's lambda $=.783, \mathrm{~F}_{7,65}=$ $2.578, p<.021$ ), and stay in the rehabilitation camp (Wilk's lambda $=.768, \mathrm{~F}_{7,65}=2.811, p<.013$ ) were highly significant. The interaction effect of death of family member(s) and stay in the rehabilitation camp was significant (Wilk's lambda $\left.=.815, \mathrm{~F}_{7,65}=2.111, p<.05\right)$.

Further, univariate tests were conducted to see how within-subject effects accounted for the variability in each of the dependent variables (Table 4). The main effect of sex was significant for intrusion $(\mathrm{F}=5.817, p<.018)$ and all the dimensions of PTG [relating to others $(\mathrm{F}=4.082, p<.047)$, new possibility $(\mathrm{F}=14.550, p<.000)$, spiritual change $(\mathrm{F}=$ $4.142, p<.046)$, appreciation of life $(\mathrm{F}=13.357, p<.000)$, and total PTG score $(\mathrm{F}=12.265, p<.001)]$. The main effect of death of family member(s) was significant for avoidance ( $\mathrm{F}$ $=11.577, p<.001)$ and only two dimensions of PTG, new possibility $(\mathrm{F}=5.736, p<.019)$ and personal strength $(\mathrm{F}=$ $5.895, p<.018)$. It was also significant for total PTG score ( $\mathrm{F}$

$=6.071, p<.016)$. Stay in the rehabilitation camp significantly affected posttraumatic stress [intrusion $(\mathrm{F}=$ 9.579, $p<.003)$, avoidance $(\mathrm{F}=10.370, p<.002)$ and IES total score $(\mathrm{F}=17.731, p<.000)]$ whereas receiving relief material significantly affected avoidance $(\mathrm{F}=5.855, p<.018)$ and IES total score $(\mathrm{F}=8.112, p<.006)$. These findings support the fifth hypothesis. The interaction effect of death of family member(s) and stay in the rehabilitation camp was significant for avoidance $(\mathrm{F}=5.941, p<.017)$ and personal strength $(\mathrm{F}=4.887, p<.030)$, thus partially supporting the sixth hypothesis. 
Table 4. Summary of tests of between-subjects effects.

\begin{tabular}{|c|c|c|c|c|c|c|}
\hline Source of Variation & Dependent Variable & $\begin{array}{l}\text { Type III Sum } \\
\text { of Squares }\end{array}$ & df & $\begin{array}{l}\text { Mean } \\
\text { Square }\end{array}$ & F & $\mathrm{p}$ \\
\hline \multirow[t]{6}{*}{ Sex } & IES Intrusion & 192.545 & 1 & 192.545 & 5.817 & .018 \\
\hline & P.TG Relating to others & 117.106 & 1 & 117.106 & 4.082 & .047 \\
\hline & PTGNew possibilities & 268.008 & 1 & 268.008 & 14.550 & .000 \\
\hline & PTG Spiritual change & 23.616 & 1 & 23.616 & 4.142 & .046 \\
\hline & PTG Appreciation of life & 70.485 & 1 & 70.485 & 13.357 & .000 \\
\hline & PTGtotal score & 2049.843 & 1 & 2049.843 & 12.265 & .001 \\
\hline \multirow[t]{4}{*}{ Death of family member } & IES Avoidance & 222.510 & 1 & 222.510 & 11.577 & .001 \\
\hline & P.IGNew possibilities & 105.659 & 1 & 105.659 & 5.736 & .019 \\
\hline & P.TG Personal strength & 90.034 & 1 & 90.034 & 5.895 & .018 \\
\hline & P.TG total score & 1014.605 & 1 & 1014.605 & 6.071 & .016 \\
\hline \multirow[t]{3}{*}{ Stay in rehabilitation camp } & IES Intrusion & 317.092 & 1 & 317.092 & 9.579 & .003 \\
\hline & IES Avoidance & 199.317 & 1 & 199.317 & 10.370 & .002 \\
\hline & IES total score & 1019.209 & 1 & 1019.209 & 17.731 & .000 \\
\hline \multirow[t]{2}{*}{ Received relief material } & IES Avoidance & 112.541 & 1 & 112.541 & 5.855 & .018 \\
\hline & IES total score & 466.298 & 1 & 466.298 & 8.112 & .006 \\
\hline Death of family member $\mathrm{X}$ & IES Avoidance & 114.180 & 1 & 114.180 & 5.941 & .017 \\
\hline Stay in rehabilitation camp & P.TG Personal strength & 74.633 & 1 & 74.633 & 4.887 & .030 \\
\hline
\end{tabular}


Table 5. t-test comparison for sex difference, life experiences (death of family members) and rehabilitation experiences (stay in rehabilitation camp and receiving relief material).

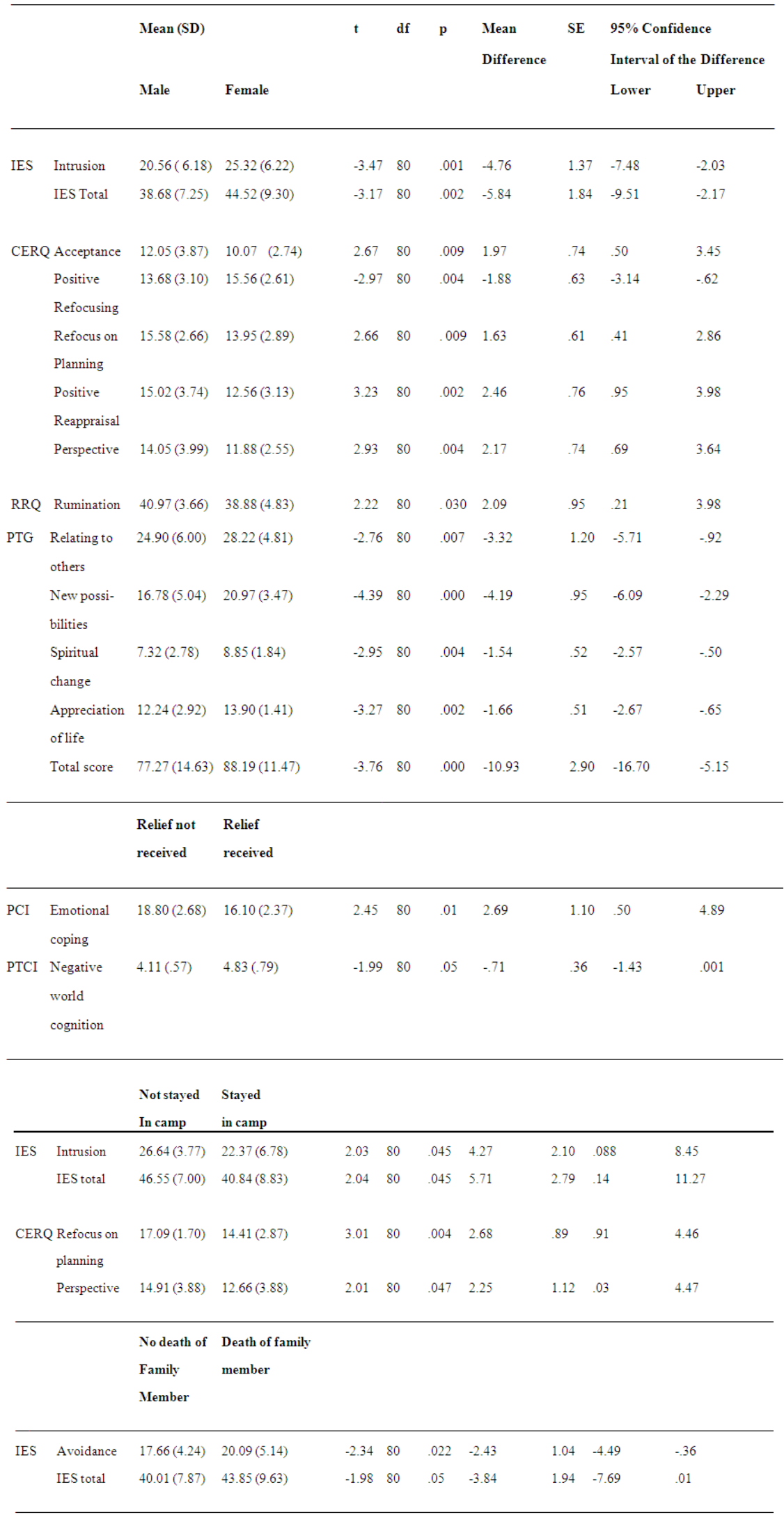




\section{t test for verifying sex differences}

Student's t-test was performed to see sex difference in terms of posttraumatic outcomes, schema changes, coping, and cognitive-emotional regulation strategies. It was also used to see the difference between those who received relief material and stayed in the rehabilitation camp and those who did not. The results indicated (see Table 5) significant sex difference in PTS and PTG. Females scored high on intrusion $(\mathrm{t}=-3.47, p<.001)$ and total IES score $(\mathrm{t}=-3.17$, $p<.002)$. They also scored high on four dimensions of PTG [relating to others $(\mathrm{t}=-2.76, p<.007)$, new possibilities $(\mathrm{t}=$ $-4.39, p<.000)$, spiritual change $(\mathrm{t}=-2.95, p<.004)$, appreciation of life $(\mathrm{t}=-3.27, p<.002)$, total score $(\mathrm{t}=-3.76$, $p<.000)$ ]. A significant sex difference was also observed in terms of cognitive-emotional regulation with males scoring high on acceptance $(\mathrm{t}=2.66, p<.009)$, refocus on planning $(\mathrm{t}$ $=2.66, p<.009)$, positive reappraisal $(\mathrm{t}=3.23, p<.002)$, and putting into perspective $(\mathrm{t}=2.93, p<.004)$ and females scoring high on positive refocusing $(\mathrm{t}=-2.97, p<.004)$.

Stay in the rehabilitation camp also seemed important. A significant difference in intrusion $(\mathrm{t}=2.032, p<.045)$ and IES total score $(\mathrm{t}=2.041, p<.045)$ was observed between those who stayed in the rehabilitation camp and those who did not with those not staying in the rehabilitation camp scoring high. With respect to cognitive-emotional regulation, those who did not stay in the rehabilitation camp were significantly different from those who stayed on refocus on planning $(\mathrm{t}=3.008, p<.004)$ and putting into perspective $(\mathrm{t}=$ $2.014, p<.047)$. Of the seven coping strategies, difference between those who received relief material and those who did not was observed only for emotional coping strategy $(\mathrm{t}=$ $2.447, p<.01)$ with those who did not receive relief material scoring high. Those who received relief material scored high on negative cognition about the world $(\mathrm{t}=-1.986, p<.05)$. Death of family members affected PTS inasmuch as those experiencing it scored high on avoidance $(\mathrm{t}=-2.34, p<.022)$ and IES total score $(\mathrm{t}=-1.984, p<.05)$. Thus, the seventh and eighth hypotheses were partially supported.

\section{Discussion}

The findings of this study suggest that overall trauma level has reduced in last 5.2 years since it was measured first by the researchers. Whereas significant decline in intrusion, avoidance, and total trauma was observed in males, the intrusion level has increased in females. The findings of this study noticeably highlight the importance of self-blame for avoidance (PTS) as well as spiritual change (PTG). The implications of various coping strategies are equally noteworthy. Self-blame refers to thoughts of blaming oneself for the experience and perhaps this could be one of the reasons why it affected avoidance reactions. It also influenced spiritual change. Trauma of this magnitude is likely to create actual situations that are discrepant of existing schemas, thus demanding the survivors to somehow reconcile with these discrepant realities. Difficulties in such reconciliation may cause symptoms such as avoidance and re-experiencing (Dalgleish, 1999). This bears resemblance to the proposition of the cognitive models of PTSD (Ehlers \& Clark, 2000). Meiser-Stedman et al. (2009) have argued that the maladaptive cognition not only correlates with symptoms but 'causally implicate' in upholding PTS reaction over time. They have also reported how maladaptive appraisals after the traumatic even mediate the association between initial and later posttraumatic stress symptoms. Even if the theory-based structuring of the analysis in the present study might not be considered strong enough to establish direction of causation, the findings lend support to the cognitive models of PTSD (Ehlers \& Clark, 2000).

Contrary to earlier studies suggesting that negative cognitions about the trauma and its consequences predict long-term PTSD in addition to initial symptom levels (Ehring et al., 2006, 2008; Halligan et al., 2003) we found self-blame playing a critical role. Haga, Kraft and Corby (2009) have reported variation in the usage of emotion regulation strategies across age, sex, and culture. To certain extent this study indicates the tendency within the samples from this part of the world to blame oneself for their life experiences. This has been consistently reported in other studies drawing sample from this culture (Hussain \& Bhushan, 2010; Hussain \& Bhushan, 2011).

The organismic valuing theory (Joseph \& Linley, 2005) draws attention to the importance of schema change for both PTS and PTG. They suggest that individuals tend to be intrinsically motivated towards rebuilding their schemas or assumptive worlds towards growth and actualization after facing traumatic events. The present findings of this study can be analyzed in the light of this theory. Finding meaning in life is an innate need of human beings (Frankl, 1964) and this is very much evident in this study too. Such quest for meaning is also associated with spirituality (Hussain \& Bhushan, 2010, Frankl, 1964).

Traumatic experiences activate certain coping strategies thus determining the perception of the event. Consequently, it mediates the relationship between trauma and its outcomes. Studies suggest that strategies such as self-blame, rumination and catastrophising are associated with increased self-reporting of symptoms. Other strategy, such as positive reappraisal is reportedly linked to decrease in self-reporting of symptoms (Garnefski et al., 2001). This study also found the significance of reflective coping. It is a state where one thinks of possible behavioral alternatives and outcomes by comparing their imagined effectiveness. This process of imagination includes analysis of the problems, resources, and alternatives and in order to generate hypothetical plan of actions. The significance of reflective coping for relating to others, personal strength, spiritual change, and appreciation of life become evident from the very nature of this coping mechanism. In instrumental support seeking, people seek advice and feedback from others. Such strategies could help in seeking new options as one gets closer to social networks. 
It can also help one see how others have succeeded overcoming challenges. This could be the reason why instrumental support seeking was important for new possibilities and appreciation of life. Appreciation of life could also get affected by one's effort to build up general resistance in order to reduce the severity of stressful outcomes. Thus, preventive coping becomes important for such appreciation.

Death of family member(s) and stay in a rehabilitation camp are some of the inevitable situation in a natural disaster of this magnitude. The findings suggest that they affected the survivors in a major way. A combination of these two experiences also has significant effect on one's psychological well-being. Although behavioural sciences researchers have not focused on the psychological consequences of relief operations, our finding conspicuously brings forth the finding that those who did not receive relief material were high on emotional coping strategy. Interestingly, those who received relief material scored were high on negative cognition about the world. By and large, the initial focus after tsunami was on debris clearage and making provision of food, water, and medical care. However, the survivors could be equally interested in burial/ funeral of the deceased and damage assessment. It merits mention that $61 \%$ of NGOs in India surveyed by Fritz Institute (2005) reported high level of unsolicited in-kind donations, creating warehousing and transshipment problems. Such oversupply can also lead to unwanted disbursement of aid materials "creating perceptions of aid "dumping" on affected families, and potentially leading to the secondary sale or trade of relief supplies" (Fritz Institute, 2005 , p. 3). Such perception can form malignant combination with crowding, claims by non-affected people, local political interference, and caste discrimination in the distribution of relief material. The findings of this study gather more strength from the population studied. Several of the issues raised here are unique to understanding posttraumatic outcomes in children in a particular social, cultural, and geographical context. It can be argued that having equal degree of exposure to trauma, an additional experience of appalling relief support issue can affect the survivour's cognitive appraisal thus affecting the posttraumatic outcomes.

Sex difference in long-lasting effect of traumatic events is reported in trauma literature. The findings of this study suggest sex difference with females significantly high on posttraumatic stress as well as posttraumatic growth. This corroborates with the earlier findings reporting sex difference in PTS and PTG (Bhushan \& Kumar, 2007; Hussain \& Bhushan, 2011; Norris et al., 2001).The male dominant culture of the affected area requires the females to engage in several indoor as well as outdoor activities such as fetching water, and so on. We have seen them standing in queue for relief material. Possibly a combination of these norms and experiences reminds them of the catastrophe. According to Voges and Romney (2003), the perception of threat to life is higher in females and this is a significant predictor of PTS.

The findings facilitate our understanding of cognitive predictors of PTS and PTG in children and adolescents. The nature of sample and the long-term follow-up adds value to this work. It breaks new ground with respect to psychological consequences of relief efforts. The findings of this study can be beneficial in evolving interventions aimed at reduction of negative appraisal. Besides preventive interventions, it might also be of use to relief agencies. Despite drawing some of the unreported findings, this study has certain limitations. The theory-based structuring of the analysis rather than a strict test of mediation is a limitation of this study as such assumption (and hence the analysis) cannot determine directions of causations. The study would have gathered strength had co-morbid conditions been taken into account. Further, it could have benefited had the remaining $36 \%$ of the earlier participants also joined. A qualitative inquiry into some of the issues would help understand things better. Personality traits, resilience, social support mechanisms, and few such variables were not included in this study. Future studies can focus on them.

\section{REFERENCES}

Ali, T., Dunmore, E., Clark, D., \& Ehlers, A. (2002). The role of negative beliefs in posttraumatic stress disorder: A comparison of assault victims and non-victims. Behavioural and Cognitive Psychotherapy, 30, 249-257.

Barakat, L. P., Alderfer, M. A., \& Kazak, A. E. (2006).Posttraumatic growth in adolescent survivors of cancer and their mothers and fathers. Journal of Pediatric Psychology, 31, 413-419.

Beiser, M. \& Wickrama, K. A. S. (2004). Trauma, time and mental health: A study of temporal reintegration and depressive disorder among Southeast Asian refugees. Psychological Medicine, 34, 899-910.

Bhushan, B. (2008). Earthquakes: Human behaviour and societal impact (3oth Nov). Keynote address at TU9-IITM Indo-German Workshop on Earthquake Engineering for Sustainable Structures.IIT Madras, India.

Bhushan, B., \& Kumar, J. S. (2007).Emotional distress and posttraumatic stress in children surviving the 2004 tsunami. Journal of Loss and Trauma, 12, 245-257.

Bhushan, B., \& Kumar, J. S. (2009). Emotional distress and posttraumatic stress in children: The impact of direct vs indirect exposure. Journal of Loss and Trauma, 14, 35-45.

Bhushan, B., Gautam, R., \& Greenglass, E. S. (2010). The Hindi adaptation and standardization of the proactive coping inventory (PCI). International Journal of Psychology and Psychological Therapy, 10:2, 79-91.

Bryant, R. A., Salmon, K., Sinclair, E., \& Davidson, P. (2007).A prospective study of appraisals in childhood posttraumatic stress disorder.Behaviour Research and Therapy, 45, 2502-2507.

Carr, V. (1988). Patients' techniques for coping with schizophrenia: 
An exploratory study. British Journal of Medical Psychology, 61, 339-352.

Dalgleish, T. (1999). Cognitive theories of post-traumatic stress disorder. In W. Yule (Ed.), Posttraumatic stress disorders: Concepts and therapy (pp. 193-220). New York: Wiley.

Dalgleish, T., Meiser-Stedman, R., \& Smith, P. (2005). Cognitive aspects of posttraumatic stress reactions and their treatment in children and adolescents: An empirical review and some recommendations. Behavioural and Cognitive Psychotherapy, 33, 459-486.

Earls, F., Smith, E., Reich, W., \& Jung, K. G. (1988).Investigating psychopathological consequences of a disaster in children: a pilot study incorporating a structured diagnostic interview. Journal of the American Academy of Child Psychiatry, 27, 90-95.

Ehlers, A. \& Clark, D. M. (2000).A cognitive model of posttraumatic stress disorder.Behaviour Research and Therapy, 38, 319-345.

Ehlers, A., Mayou, R. A., \& Bryant, B. (2003). Cognitive predictors of posttraumatic stress disorder in children: Results of a prospective longitudinal study. Behaviour Research and Therapy, 41, 1-10.

Ehring, T., Ehlers, A., \& Glucksman, E. (2006).Contribution of cognitive factors to the prediction of post-traumatic stress disorder, phobia and depression after motor vehicle accidents. Behaviour Research and Therapy, 44, 1699-1716.

Ehring, T., Ehlers, A., \& Glucksman, E. (2008). Do cognitive models help in predicting the severity of posttraumatic stress disorder, phobia, and depression after motor vehicle accidents? A prospective longitudinal study. Journal of Consulting and Clinical Psychology, 76, 219-230.

Eisenberg, N., Fabes, R.A., Guthrie, I.K., \& Reiser, M. (2000). Dispositional emotionality and regulation: their role in predicting quality of social functioning. Journal of Personality and Social Psychology, 78, 136-157.

Evers, A. W. M., Kraaimaat, F. W., Van Lankveld, W., Jongen, P. J. H., Jacobs, J. W. G., \& Bijlsma, J. W. J. (2001). Beyond unfavorable thinking: The Illness Cognition Questionnaire for Chronic Diseases. Journal of Consulting and Clinical Psychology, 69, 1026-1036.

Fletcher, K. E. (1996). Childhood posttraumatic stress disorder. In: E. J. Mash, \& R. Barkley (Eds.), Child psychopathology ( pp. 242-276). New York: Guilford Press.

Foa, E. B., Ehlers, A., Clark, D.M., Tolin, D. F., \& Orsillo, S. M. (1999). The Posttraumatic Cognitions Inventory (PTCI): Development and validation. Psychological Assessment, 11, 303-314.

Foa, E. B., Steketee, G., \& Rothbaum, B. O. (1989). Behavioral/cognitive conceptualization of posttraumatic stress disorder. Behavior Therapy, 20, 155-176.

Frankl, V. E. (1964). Man's search for meaning: An introduction to logotherapy. London: Hodder and Stoughton.

Fritz Institute (2005). Lessons from the Tsunami Survey of Non-Governmental Organizations in India and Sri Lanka. Retrieved November 30, 2010, from http://www.fritzinstitute.org/PDFs/findings/NGOsReport.pdf

Garnefski, N., Kraaij, V., \& Spinhoven, Ph. (2001). Negative life events, cognitive emotion regulation and depression. Personality and Individual Differences, 30, 1311-1327.

Garnefski, N., Kraaij, V., \& Spinhoven, Ph. (2002). Manual for the use of the cognitive emotion regulation questionnaire. Leiderdorp, The Netherlands: DATEC.

Greenglass, E. (2002). Proactive coping. In E. Frydenberg (Ed.), Beyond coping: Meeting goals, vision, and challenges. London: Oxford University Press, (pp. 37-62).

Greenglass, E., Fiksenbaum, L., \& Eaton, J. (2006).The relationship between coping, social support, functional disability and depression in the elderly. Anxiety, Stress and Coping, 19, 15-31.

Greenglass, E., Schwarzer, R., Jakubiec, D., Fiksenbaum, L., \& Taubert, S. (1999). The proactive coping inventory (PCI): A multidimensional research instrument. Paper presented at the 20th International Conference of the Stress and Anxiety Research Society (STAR), Cracow, Poland, July 12-14.

Griensven, F. V., Chakkraband, M. L. S., Thienkrua, W., Pengjuntr, W., Cardozo, B. L., Tantipiwatanaskul, P., Mock, P. A., Ekassawin, S., Varangrat, A., Gotway, C., Sabin, M., \& Tappero, J. W. (2006). Mental health problems among adults in tsunami-affected areas in southern Thailand. JAMA, 296, 537-548.

Haga, S., Kraft, P., \& Corby, E. K. (2009). Emotion regulation: Antecedents and well-being outcomes of cognitive reappraisal and expressive suppression in cross-cultural samples. Journal of Happiness Studies, 10, 271-291.

Halligan, S. L., Michael, T., Clark, D. M., \& Ehlers, A. (2003). Posttraumatic stress disorder following assault: the role of cognitive processing, trauma memory, and appraisals. Journal of Consulting and Clinical Psychology, 71, 419-431.

Hallis, D. \& Slone, M. (1999). Coping strategies and locus of control as mediating variables in the relation between exposure to political life events and psychological adjustment in Israeli children. International Journal of Stress Management, 6, 105-123.

Helgeson, V. S., Reynolds, K. A., \& Tomich, P. L. (2006). A meta-analytic review of benefit finding and growth. Journal of Consulting and Clinical Psychology, 74, 797-816.

Horowitz, M. (1986). Stress response syndromes. Northville, NJ: Jason Aronson.

Horowitz, M. J., Wilner, N., \& Alvarez, W. (1979). Impact of event scale: A measure of subjective stress. Psychosomatic Medicine, 41, 209-218.

Hussain, D. \& Bhushan, B. (2010). Cultural factors promoting coping among Tibetan refugees: A qualitative investigation. Mental Health, Religion \& Culture, Retrieved August 18, 2010, from http://dx.doi.org/10.1080/13674676.2010.497131.

Hussain, D. \& Bhushan, B. (2011). Posttraumatic stress and growth among Tibetan refugees: The mediating role of cognitive-emotional strategies, Journal of Clinical Psychology, 67, 1-16.

Hussain, D. (2010). Posttraumatic stress \& growth among Tibetan refugees: The role of cognitive-emotional processing \& spiritual belief. Unpublished doctoral dissertation.

John, P. B., Russell, S., \& Russell, P. S. (2007). The prevalence of posttraumatic stress disorder among children and adolescents affected by tsunami disaster in Tamil Nadu. Disaster Management and Response, 5, 3-7.

Joseph, S. \& Williams, R. (2005). Understanding posttraumatic 
stress: theory, reflections, context and future. Behavioural and Cognitive Psychotherapy, 33, 423-441.

Joseph, S., \& Linley, P. A. (2005). Positive adjustment to threatening events: An organismic valuing theory of growth through adversity. Review of General Psychology, 9, 262-280.

Levine, S. Z., Laufer, A., Hamama-Raz, Y., Stein, E., \& Solomon, Z. (2008). Posttraumatic growth in adolescence: Examining its components and relationship with PTSD. Journal of Traumatic Stress, 21, 492-496.

Lev-Wiesel, R., \& Amir, M. (2003).Posttraumatic growth among Holocaust child survivors. Journal of Loss and Trauma, 8, 229-237.

Lonigan, C. J., Shannon, M. P., Taylor, C. M., Finch, A. J., \& Sallee, F. R. (1994). Children exposed to disaster: Risk factors for the development of posttraumatic symptomatology. Journal of the American Academy of Child and Adolescent Psychiatry, 33, 94-105.

Lori, D. \& Lawrence, J. S. (2003). Posttraumatic stress disorder in children and adolescents: A review and analysis. Clinical Child and Family Psychology Review, 3, 135-154.

MacKinnon, D. P., Warsi, G., \& Dwyer, J. H. (1995). A simulation study of mediated effect measures. Multivariate Behavioral Research, 30, 41-62.

Meiser-Stedman, R. (2002). Towards a cognitive-behavioral model of PTSD in children and adolescents. Clinical Child and Family Psychology Review, 5, 217-232.

Meiser-Stedman, R., Dalgleish, T., Glucksman, E., Yule, W., \& Smith, P. (2009). Maladaptive cognitive appraisals mediate the evolution of posttraumatic stress reactions: A 6-month follow-up of child and adolescent assault and motor vehicle accident survivors. Journal of Abnormal Psychology, 118, 778-787.

Meiser-Stedman, R., Dalgleish, T., Smith, P., Yule, W., \& Glucksman, E. (2007). Diagnostic, demographic, memory quality, and cognitive variables associated with acute stress disorder in children and adolescents. Journal of Abnormal Psychology, 116, 65-79.

Milam, J. E., Ritt-Olson, A., \& Unger, J. (2004).Posttraumatic growth among adolescents. Journal of Adolescent Research, 19, 192-204.

Neuner, F., Schauer, E., Catani, C., Ruf, M., \& Elbert, T. (2006). Post-tsunami stress: A study of posttraumatic stress disorder in children living in three severely affected regions in Sri Lanka. Journal of Traumatic Stress, 19, 339-347.

Norris, F. H. (2002). Psychosocial consequences of disasters. PTSD Research Quarterly, 13, 1-3.

Norris, F. H., Perilla, J. L., Ibañez, G. E., \& Murphy, A. D. (2001). Sex differences in symptoms of posttraumatic stress disorder: Does culture play a role? Journal of Traumatic Stress, 14, 7-28.

Owens, G. P. \& Chard, K. M. (2001).Cognitive distortions among women reporting childhood sexual abuse. Journal of Interpersonal Violence, 16, 178-191.

Pietilä, A. M. \& Tervo, A. (1998).Elderly Finnish people's experiences with coping at home. International Journal of Nursing Practice, 4, 19-24.

Powell, S., Rosner, R., Butollo, W., Tedeschi, R. G., \& Calhoun, L. G. (2003). Posttraumatic growth after war: A study with former refugees and displaced people in Sarajevo. Journal of Clinical Psychology, 59, 71-83.

Salmon, K. \& Bryant, R. A. (2002). Posttraumatic stress disorder in children: the influence of developmental factors. Clinical Psychology Review, 22, 163-188.

Salmon, K., Sinclair, E., \& Bryant, R. A. (2007). The role of maladaptive appraisals in child acute stress reactions. British Journal of Clinical Psychology, 46, 203-210.

Sharkansky, E. J., King, D. W., King, L. A., \& Wolfe, J. (2000). Coping with Gulf war combat stress: Mediating and moderating effects. Journal of Abnormal Psychology, 109, 188-197.

Stallard, P. (2003). A retrospective analysis to explore the applicability of the Ehlers and Clark (2000) cognitive model to explain PTSD in children. Behavioural and Cognitive Psychotherapy, 31, 337-345.

Suliman, S., Kaminer, D., Seedat, S., \& Stein, D. (2005). Assessing post-traumatic stress disorder in South African adolescents: using the child and adolescent trauma survey (CATS) as a screening tool. Annals of General Psychiatry, 4, 2.

Tedeschi, R. G., \& Calhoun, L. G. (1995). Trauma and transformation: growing in the aftermath of suffering. Thousand Oaks, CA: Sage.

Tedeschi, R. G., \& Calhoun, L. G. (1996). The Posttraumatic Growth Inventory: Measuring the positive legacy of trauma. Journal of Traumatic Stress, 9, 455-471.

Tedeschi, R. G., \& Calhoun, L. G. (2004). Posttraumatic growth: Conceptual foundations and empirical evidence. Psychological Inquiry, 15, 1-18.

Tedeschi, R. G., Park, C. L., \& Calhoun, L. G. (1998). Posttraumatic growth: Positive changes in the aftermath of crisis. Mahwah, NJ: Erlbaum.

Thoits, P. A. (1995). Stress, coping, and social support processes: Where are we? What next? Journal of Health and Social Behavior (Extra Issue), 53-79.

Thompson, R. A. (1991). Emotion regulation and emotional development. Educational Psychology Review, 3, 269-307.

Thompson, R. A., \& Calkins, S. D. (1996). The double-edged sword: emotional regulation for children at risk. Development and Psychopathology, 8, 163-182.

Vernon, L. L., Dillon, J. M., \& Steiner, A. R. W. (2009). Proactive coping, gratitude, and posttraumatic stress disorder in college women. Anxiety, Stress \& Coping, 22, 117-127.

Vijayakumar, L., Kannan, G. K., \& Daniel, S. J. (2006). Mental health status in children exposed to tsunami. International Review of Psychiatry, 18, 507-513.

Voges, M. A. \& Romney, D. M. (2003).Risk and resiliency factors in posttraumatic stress disorder.Annals of General Hospital Psychiatry, 2, 4.

Wickrama, K.A.S. \& Kaspar, V. (2007). Family context of mental health risk in Tsunami-exposed adolescents: Findings from a pilot study in Sri Lanka. Social Science \& Medicine, 64, 713-723.

Yule, W. (1992). Posttraumatic stress disorder in child survivors of shipping disasters: the sinking of the 'Jupiter'. Psychotherapy and Psychosomatics, 57, 200-205. 